US bomb tests

\section{Radiation tests underestimated?}

Washington

THE US Department of Defense (DoD) was criticized last week by the General Accounting Office (GAO) for underestimating the exposure to radiation of 42,000 service veterans who participated in the 1946 "Operation Crossroads" atomic weapons tests at Bikini Atoll. According to GAO, the DoD's assessment, on which basis the Veteran's Administration has so far rejected medical claims based on radiation exposure, may underestimate or entirely overlook significant beta exposure, while the internal alpha dose may be underestimated by a factor of 5 to 10 .

The two Crossroads explosions, the first above water and the second below, were the first atmospheric weapons tests in peacetime, and radiological protection procedures were crude or non-existent. Decontamination procedures, showering and changing of clothes, for men working to clean up ships moored near the explosion, were only instituted six days after the second (and much dirtier) test, as the extent of contamination became apparent. The clean-up was eventually halted because of high radioactivity level, but only 6,300 of the 42,000 participants in Crossroads wore film badge dosimeters, and none wore badges every day.

Because records are so incomplete, DoD in 1977 asked its Defense Nuclear Agency to reconstruct exposures by extrapolation from known cases. The agency's conclusion, published last year, was that 93 per cent of those involved received exposures of less than $0.5 \mathrm{rem}$, and that all received less than 1.7 rem (the permitted total for radiation workers in the United States today is 5 rem per year). But GAO has identified several respects in which it believes DoD's analysis is in error.

Most doubt centres on the accuracy and interpretation of film badges. The badges did not work in the way expected, possibly

because of the effect of humidity, and GAO believes beta exposures could as a result have been seriously underestimated: 100 per cent error can be expected at the lower end of the range, for which DoD made no allowance. GAO also finds that personnel decontamination and protection procedures assumed by DoD were not in effect (immediately after the tests) or were widely ignored; in none of the photographs of the clean-up operation are the men wearing protective clothing.

DoD has formally disagreed with many of GAO's conclusion, but $\mathrm{GAO}$ retorts that DoD's comments are based on incor-

\section{Computers}

Berkeley, California

Conventions held sacred for decades by the designers of computer hardware and software are being seriously challenged by computer researchers at the University of California, Berkeley. At the fore of the challenge is a new development in microchip technology which has simplified the design of the electronics needed for computers and jettisoned redundant and laborious machine coding.

That part of the Berkeley revolution began about five years ago, but its proponents believe the change is at last about to be accepted in the industry despite the controversy the ideas have generated and the hostility they have provoked. According to David Patterson, an associate professor of the Computer Science Division at Berkeley, and one of the creators of the new machines, "1986 will be the year when we see what happens".

The new computer designs were arrived at by inspecting a VAX minicomputer and identifying many machine code instructions that were never used in most com-

\title{
Putting back the clock
}

\section{Soviets admit AIDS cases}

The Soviet Union has now admitted that AIDS (acquired immune deficiency syndrome) has reached the Soviet Union. Interviewed in the newspaper Sovetskaya Kultura, Dr Viktor Zhandrov, a leading Soviet virologist, denied the growing rumours that there are "numerous" cases of AIDS in the Soviet Union but acknowledged that there had been an "insignifcant number of cases" reported.

This comes less than two months after Soviet denials that there were any cases of AIDS in the Soviet Union (see Nature 317 , $659 ; 1985$ ).

Dr Zhandrov's article is less polemic in tone than previous Soviet statements on the disease, which stressed its connection in the West with drug addiction (relatively

rare in the Soviet Union) and homosexuality (which is illegal).

He stressed, moreover, that the disease seems to have originated in central African monkeys. This is in marked contrast to a recent trend in the Soviet media to attribute AIDS to United States bacteriological warfare experiments; although much of this reporting seems to be anecdotal (for example, that in Kenya AIDS has developed in proximity to a US base), not all of it has been directed at Third World audiences. In particular, on 30 October, Literaturnaya Gazeta quoted the Indian popular daily, The Patriot, to the effect that AIDS was developed in the United States at Fort Detrick as a weapon against the black and homosexual communities. Vera Rich rect and unsupported statements and misinterpreted documents. GAO's recommendation is that DoD be required to revise its estimates to take account of the sources of error now identified. If the revisions are carried out and GAO's conclusions validated, the implications could be great for the 500 veterans' disability claims relating to Crossroads, as well as to the many thousands of others relating to different tests; the Veterans Administration has already indicated that it wants to extend GAO's findings. The GAO report which was requested by Senator Alan Cranston of the Senate Veterans' Affairs Committee, will doubtless form the background to what may be expected to be stormy congressional hearings in the near future.

Tim Beardsley

putational exercises. In that inspection. 304 such instructions were reduced to one tenth that number. So was born the Berkeley computer concept, called Reduced Instruction Set Computers (RISC).

The RISC machines turned the clock back in computer design. The evolution of computers - mainframe, mini and the micro designs in the 1970 s and 1980 s used volumes of complicated instructions (the basic code programming the machines) and relied more and more on intricate and faster microelectronics to control that complex structure. A computer evolved within the computer, controlling these arrays of instruction codes, most of which were never used.

Berkeley's idea was to minimize the coded instructions needed to operate the machine and, at the same time, to design a simpler microchip. The RISC microchip made at Berkeley, the hub of the new machine, now has over 41,000 transistors and 6032 -bit registers. It can be fabricated on silicon down to a gate size of $4 \mu \mathrm{m}$ with a speed of $500 \mathrm{~ns}$ per instruction.

Berkeley's research has been matched by that of others at Stanford University, IBM at Yorktown Heights and now at Hewlett Packard. Says Patterson, "Hewlett Packard is going to base its whole next generation on these ideas". IBM is rumoured to be developing workstations on the same principles.

Patterson is confident that RISC is a forward step despite its apparent resort to simpler technology. "Many people find this to be a ridiculously bad idea. It's a deevolution of computer design ... a dangerous concept. Shouldn't be talked about". Patterson and his Berkeley team are continuing to talk about it, and are developing the concept even further to see if the RISC machines can be further enhanced for the scientific and academic use of computers. One such application to be pursued is the use of RISC for artificial intelligence. 